\title{
AN ASSISTIVE DEVICE FOR SMOKING
}

\author{
By Melvin J. Goldberg, M.D., and Linda J. Davis, O.T.R.
}

Department of Rehatilitation Medicine. The Brooklyn-Cumberland Medical Centre, Brooklyn, New York II20I, and Physical Medicine Service, Naval Hospital, Oakland California

Many tetraplegic patients enjoy smoking but, as yet, no entirely satisfactory assistive device has become available to enable these patients to handle smoking independently or with a minimum of assistance.

Our experience with the combination ashtray-cigarette holder, placed at bedside or on an overbed table and connected to the patient by tubing, have demonstrated several disadvantages. In the first place, the patients usually do not like the taste of the smoke after it has traversed the tubing. Secondly, the tubing becomes blocked with sticky deposits after a relatively short period of use. This situation can be corrected with frequent changes of tubing, which can easily become a constant inconvenience to the patient or those caring for him. However, there is minimal expense since used intravenous infusion tubing can be used.

Other methods of assistance in smoking require a hospital staff member or volunteer to be in attendance. Assistance is needed to remove ashes from the cigarette and to extinguish it in order to prevent burning of the patient's lips or dropping of the cigarette on to the patient's clothing or bed. These methods are satisfactory, but neither conducive to independence nor conservative in the use of personnel.

A new device, devised by one of the authors (L. J. D.) and constructed in the Occupational Therapy Department, has been put into use at this hospital to assist in the total rehabilitation of the tetraplegic patient. We have called the device a 'Smoking Splint' for want of a more descriptive term. The Smoking Splint consists of two basic parts: a standard commercial utensil holder with Velcro fastener and an ordinary stainless-steel table fork. Several turns of masking tape are wound on to the handle of the fork to prevent it from slipping out of the utensil holder. The two lateral tines on each side of the fork are squeezed together with pliers to create a V-shaped area between the two middle tines. A rivet with the head removed is tapped gently over the tines which have already been squeezed tightly together (fig. I). The head of the rivet is removed with a hacksaw or jeweller's saw and the tip smoothed with a file or grindstone. The rivets are placed over the tines in order to prevent damage to the patient's face in the event of a spastic movement of the arm. Any blunt material could be used to accomplish this dual purpose of preventing facial damage and of maintaining the $\mathrm{V}$ shape of the middle area.

The fork is inserted into the utensil holder and the holder placed on the patient's hand. A cigarette is wedged tightly into the V. It can then be lighted and smoked down to its point of contact with the tines. It will then extinguish itself and can be removed later.

The opinions or assertions expressed herein are the private ones of the authors and are not to be construed as official or as necessarily reflecting the views of the Medical Department of the Navy or of the Naval Service at large. 


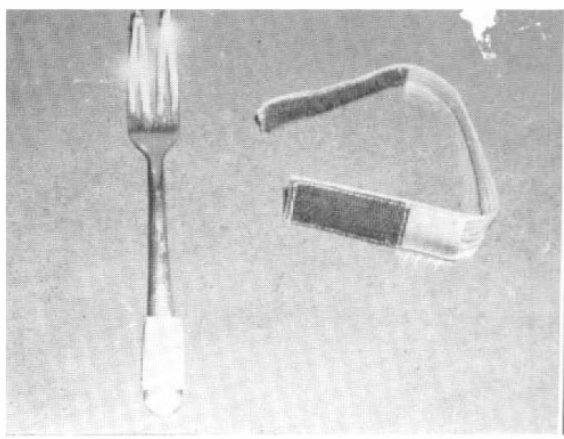

FIG. I

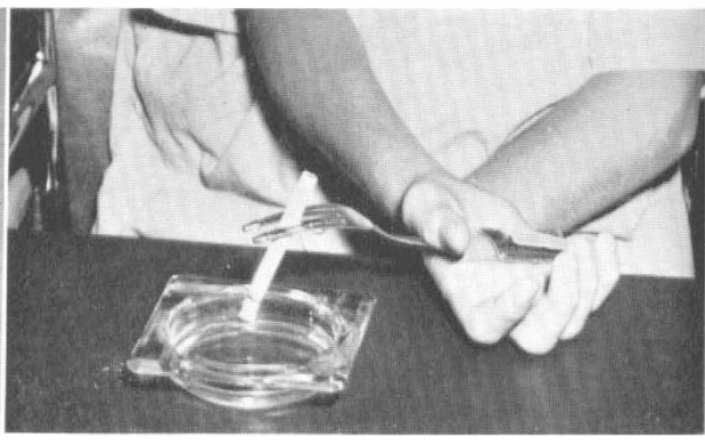

FIG. 2

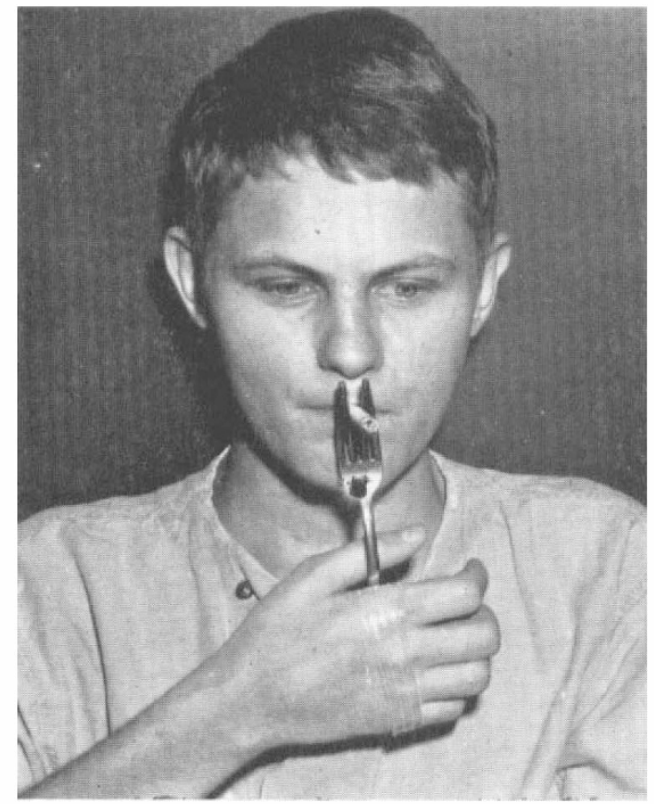

Fig. 3

Fig. I.-The stainless-steel fork has several turns of masking tape around the handle and has the tines on each side held together by the head of a rivet. The plastic utensil holder has a Velcro fastener.

Fig. 2.-Most patients can tap the cigarette on a nearby ashtray to remove the ash.

Fig. 3. - The patient flexes his elbow to bring the cigarette to his mouth. 
It is necessary for the patient, such as a $\mathrm{C}_{5}$ or 6 tetraplegic, to have enough elbow control to be able to tap the cigarette on , nearby ashtray (fig. 2), and to bring the cigarette to his mouth (fig. 3).

We have found this simple smoking splint extremely useful, practical, and timesaving. It is inexpensive, simple to construct, easily transported, and requires no special equipment or training for its use. In addition, it facilitates independence and requires minimal assistance with maximum relative safety.

\section{Materials Needed:}

I. One commerical utensil holder with Velcro fastener.

2. One table fork, stainless steel, with four tines.

3. Two rivets.

4. Pliers.

5. Masking tape. 